'Fundação Oswaldo Cruz (Fiocruz), Escola Nacional de Saúde Pública Sergio Arouca (Ensp), Núcleo de Estudos e Pesquisas de Recursos Humanos em Saúde (NERHUS) - Rio de Janeiro (RJ), Brasil. stiebler@ensp.fiocruz.br

2 Fundação Oswaldo Cruz (Fiocruz), Escola Naciona de Saúde Pública Sergio Arouca (Ensp), Núcleo de Estudos e Pesquisas de Recursos Humanos em Saúde (NERHUS) - Rio de Janeiro (RJ), Brasil.

moyses@ensp.fiocruz.br

\section{Trajetória da graduação das catorze profissões de saúde no Brasil}

\section{Graduation trajectory of the fourteen health professions in Brazil}

Ana Luiza Stiebler Vieira', Neuza Maria Nogueira Moyses²

RESUMO O estudo quantitativo e descritivo objetivou analisar a trajetória das catorze graduações em saúde, apontar a ociosidade de vagas e identificar a presença e a dimensão da educação a distância. A partir dos Censos da Educação Superior, os cursos em 1995, 2004 e 2015, as vagas e os concluintes de 1995 a 2015, as relações vagas x ingressos e ingressos x concluintes constituíram as variáveis e os indicadores de análise. Foram observadas grande expansão, iniquidade geográfica e privatização da formação, significativa ociosidade de vagas e inadequada oferta de formação a distância. Conclui-se que constitui agenda prioritária o ordenamento de recursos humanos em saúde coerente com as diretrizes e os princípios do Sistema Único de Saúde (SUS).

PALAVRAS-CHAVE Educação em saúde. Recursos humanos em saúde. Educação a distância.

ABSTRACT The quantitative and descriptive study sought to analyze the trajectory of the fourteen undergraduate studies in healthcare, to note the idleness of vacancies and to identify the presence and the dimension of the distance education. Based on the Higher Education Census, the clases of 1995, 2004 and 2015, the vacancies and the graduates from 1995 to 2015, the relations vacancies $x$ admissions and admissions $x$ gradautes made up the variables and the analysis indicators. A large expansion, geographic iniquity and privatization of graduation, significant idleness of vacancies and inadequate availability of distance education have been observed. It is concluded that the planning of healthcare human resources in accordance with the directives and principles of the Unified Health System (SUS) is a priority agenda.

KEYWORDS Health education. Health manpower. Education, distance. 


\section{Introdução}

Na ambientação de reformas administrativas da década de 1990, no País, o setor da educação, em 1996, passou a ter a sua política pautada na Lei de Diretrizes e Bases da Educação Nacional (LDB) (BRASIL, 1996). A promulgação desta Lei no 9.394 foi um importante instrumento para o crescimento de cursos em todas as áreas do conhecimento, tendo em vista que proporcionou flexibilizações significativas no sistema de ensino, tais como: a autonomia didático-científica, com extinção de currículos mínimos; a liberdade na composição da carga horária para integralização dos currículos, das especificações das unidades de ensino, com orientação de evitar o prolongamento da duração dos cursos e de fixar currículos dos cursos e programas; a recomendação de que cada curso adotasse as suas diretrizes curriculares, mas com a indicação de construção conjunta de diretrizes curriculares específicas para cada curso com as instituições de ensino e o Ministério da Educação (ME); a liberdade de abertura, fixação de vagas e fechamento de cursos; a não obrigatoriedade do vestibular para o ingresso no ensino superior; e a autonomia administrativa e de gestão financeira das instituições de ensino.

Em 1997, o Decreto n ${ }^{\circ} 2.306$ (BRASIL, 1997) reorganizou o Sistema Federal de Ensino; estabeleceu a liberdade quanto à forma de organização das entidades mantenedoras privadas de ensino superior; classificou como Centros Universitários aquelas instituições de ensino pluricurriculares que abranjam uma ou mais áreas do conhecimento, caracterizadas pela excelência do ensino comprovada pela qualificação do corpo docente, mas sem exigência de desenvolvimento de pesquisa; e, como destaque, instituiu a prévia avaliação do Conselho Nacional de Saúde (CNS) quanto à criação de cursos de Medicina, Odontologia e Psicologia. Esse Decreto foi revogado sequencialmente pelo Decreto $\mathrm{n}^{\circ} 3.860$, de 09 de julho de 2001
(BRASIL, 2001A), que incluiu a abertura de cursos de graduação em Direito com avaliação da Ordem dos Advogados do Brasil (OAB), pelo Decreto $\mathrm{n}^{\circ}$ 5.773, de 10 de maio de 2006 (BRASIL, 2006), e, finalmente, pelo Decreto $\mathrm{n}^{0} 8.754$, de 10 de maio de 2016 (BRASIL, 2016), que incluiu, também, a graduação em Enfermagem na avaliação do CNS; reafirmou a apreciação dos Conselhos Federais e da OAB para, em caráter opinativo, se manifestarem quanto à abertura dos cursos de graduação em Medicina, Odontologia, Psicologia e Direito; atualizou as regras e funções de regulação, supervisão e avaliação do sistema de ensino superior a cargo do ME; confirmou a classificação das instituições em Universidades, Centros Universitários e Faculdades; e estabeleceu para o credenciamento como Universidade ou Centro Universitário (com as consequentes prerrogativas de autonomia) a dependência do credenciamento específico da instituição já credenciada, em funcionamento regular, de 'padrão satisfatório de qualidade'.

Como importantes políticas de Estado, contribuintes para a expansão da oferta de cursos e vagas, bem como para o aumento da acessibilidade, da manutenção e da inclusão de alunos no ensino superior, além da LDB, de 1996, destacam-se: o Plano Nacional de Educação, de 2001 a 2010 (PNE) (BRASIL, 2001B), que objetivou prover a oferta de educação superior até o final da década para $30 \%$ da população de 18 a 24 anos; o Programa de Financiamento Estudantil (Fies) (BRASIL, 2001C) e o Programa Universidade para Todos (Prouni) (BRASIL, 2005), direcionados exclusivamente às instituições privadas de ensino como estratégias de manutenção do nível de matrículas através, respectivamente, do financiamento e da concessão de bolsas integrais e parciais de estudo; o Programa de Apoio a Planos de Reestruturação e Expansão das Universidades Federais (Reuni) (BRASIL, 2007A); a Lei ${ }^{\circ} 12.711$, de 2012, conhecida como a lei de cotas, em busca da correção da desigualdade de oportunidade 
através da inclusão social e racial no ensino superior nas universidades federais e, também, nas instituições federais de ensino técnico de nível médio (BRASIL, 2012); e o Plano Nacional de Educação (PNE), de 2014 a 2024 (BRASIL, 2014), o qual prossegue com a política de expansão do ensino superior e o aumento de inclusão para $33 \%$ da população de 18 a 24 anos nas graduações brasileiras.

Como medidas regulatórias, diante da flexibilidade advinda da LDB, de 1996, e perante o PNE, de 2001, e por recomendações desses, após intenso processo de discussão das instituições de ensino, dos conselhos e das associações profissionais e do ME, de 2001 a 2014, foram construídas para as catorze profissões de saúde (consideradas como tal pelo CNS através da Resolução no 287 , de 8/10/1998) as suas Diretrizes Curriculares, regulamentadas em diferentes Pareceres do Conselho Nacional de Educação/Câmara de Educação Superior (CNE/CES): em 2001, Medicina' (atualizada em 2014) ${ }^{2}$, Nutrição ${ }^{3}$ e Enfermagem ${ }^{4}$; em 2002, Serviço Social5, Fisioterapia ${ }^{6}$, Ciências Biológicas 7 Fonoaudiologia ${ }^{8}$, Farmácia 9 , Terapia Ocupacional10 e Odontologian'; em 2003, Medicina Veterinária ${ }^{12}$ e Biomedicina ${ }^{13}$; em 2004, Psicologia ${ }^{14}$ (atualizada em 2011) ${ }^{15}$; e, finalmente, em 2012, Educação Física ${ }^{16}$. As Diretrizes Curriculares Nacionais definiram para cada profissão o perfil profissional, as competências e habilidades, os conteúdos curriculares, estágios e atividades complementares, a organização do curso, o seu acompanhamento e a avaliação. Com acentuada participação e demanda das entidades profissionais por regulação no ensino, em 2007 e 2009, o ME restabeleceu, através da Resolução CNE/CES n ${ }^{0} 2^{17}$ e da Resolução CNE/CES $n^{0} 4^{18}$, a carga horária mínima de integralização e duração dos cursos de graduação presenciais. Em 2007, 4.000 horas para as graduações de Medicina Veterinária, Psicologia e Odontologia, 3.000 horas para o Serviço Social e 7.200 horas para a Medicina. Em 2009, 4.000 horas para Enfermagem, Farmácia e Fisioterapia, e 3.200 horas para
Biomedicina, Ciências Biológicas, Educação Física, Fonoaudiologia, Nutrição e Terapia Ocupacional.

A reforma do setor educativo, segundo análise do período de 1995 a 2003, de Vieira et al. (2006), Vieira e Amâncio Filho (2006), apresentou marcantes mudanças na formação superior em saúde: o crescimento acelerado de cursos, a sua concentração geográfica e a forte tendência de privatização do ensino. Tais resultados são corroborados pelos estudos de 1991 a 2004, de Haddad et al. (2006), que também destacaram a ociosidade de vagas, e de Pierantoni et al. (2012), este último com análise restrita ao período de 2000 a 2010.

Objetiva-se, portanto, analisar a trajetória da graduação das catorze profissões de saúde entre os anos de 1995 a 2015; apontar a ociosidade de vagas e identificar a presença e a dimensão do ensino a distância entre as graduações em saúde. Inspira-se na perspectiva de que os resultados possam contribuir para a formulação de políticas do setor educacional e do setor saúde na gestão da formação e do trabalho em saúde, assim como, também, com subsídios para as entidades brasileiras das profissões de saúde e para os estudos comparativos internacionais, além da importância acadêmica, de geração e divulgação desse conhecimento.

\section{Metodologia}

Para este estudo de cunho quantitativo e descritivo, utilizaram-se, no período de 1995 a 2015, os dados públicos dos Censos da Educação Superior do Instituto Nacional de Estudos e Pesquisas Educacionais Anísio Teixeira (Inep) (INEP, 2015B), do Ministério da Educação. A finalização, em 2015, deve-se à última disponibilidade de dados do Inep.

$\mathrm{Na}$ trajetória das graduações, foram utilizados os cursos na modalidade de formação presencial como variável de análise, destacando, em 1995 e 2015, a participação dos cursos das catorze formações em saúde entre

\footnotetext{
1 Resolução CNS/CES no 4 , de novembro de 2001. 2 Resolução CNS/CES no 3 , de 20 de junho de 2014.

3 Resolução CNS/CES no 5 , de 7 de novembro de 2001.

4 Resolução CNS/CES no 3, de 7 de novembro de 2001.

5 Resolução CNS/CES no 15 , de 13 de março de 2002.

6 Resolução CNS/CES no 4 de 19 de fevereiro de 2002.

7 Resolução CNS/CES no 7 , de 11 de marco de 2002.

8 Resolução CNS/CES no 5 , de 19 de fevereiro de 2002.

9 Resolução CNS/CES no 2 , de 19 de fevereiro de 2002.

10 Resolução CNS/CES no 6 , de 19 de fevereiro de 2002.

1 Resolução CNS/CES no 3 , de 19 de fevereiro de 2002.

12 Resolução CNS/CES no 1 , de 18 de fevereiro de 2003. 13 Resolução CNS/CES no 2 , de 18 de fevereiro de 2003.

14 Resolução CNS/CES no 8 , de 7 de maio de 2004.

15 Resolução CNS/CES no 5 , de 15 de março de 2011. 16 Resolução CNS/CES no 255, de 6 de junho de 2012. 17 Resolução CNE/CES no 2, de 18 de junho de 2007.

18 Resolução CNE/CES no 4 de 7 de abril de 2009.
} 
o total da oferta de cursos para todas as áreas do conhecimento, a oferta mais atual e disponível, ou, em 2015, do total de cursos em cada graduação em saúde e das catorze graduações, o crescimento absoluto e percentual dos cursos de saúde entre 1995 e 2015 (com a devida atenção para o fato de que os cursos em cada graduação não podem se somar ao longo dos anos) e a privatização da oferta dos cursos e a distribuição geográfica, em 2015, comparadas com o ano de 1995. A análise do crescimento da oferta de cursos, bem como da sua privatização e distribuição geográfica, foi intercalada por anos correspondentes ao período anterior (1995) e posterior à promulgação da LDB de 1996, de forma mais próxima e mais distante (respectivamente, os anos de 2004 e 2015), como também no último ano (2015), após a implementação de políticas públicas relacionadas à maior acessibilidade para a formação superior no País. A opção de intervalos na análise do crescimento também se justifica pelo limite deste formato de publicação (artigo) para apresentação das varáveis (cursos, vagas e egressos) em cada uma das catorze profissões na série de vinte e um anos.

A variável vagas (também provenientes de cursos presenciais) foi utilizada para análise da trajetória das graduações em saúde de 1995 a 2015 , verificando a oferta total de vagas em todo o período para todas as áreas do conhecimento e para as catorze graduações em saúde. Os concluintes das graduações presenciais constituíram outra variável de análise da trajetória das graduações, sendo verificado crescimento absoluto e percentual entre os anos 1995 e 2015 e, nesses mesmos anos, a participação absoluta e percentual dos concluintes oriundos das instituições públicas e privadas de ensino, como também a distribuição geográfica dos concluintes nas regiões brasileiras. Em todo o período, de 1995 a 2015, foi verificado o total de concluintes em todas as áreas do conhecimento e o total de concluintes também em todo o período, nas catorze graduações em saúde oriundas de instituições públicas e privadas. Para apontar a ociosidade de vagas nos cursos presenciais, lança-se mão de estudos anteriores acerca da relação vagas $\mathrm{x}$ ingressos (Humerez e Jankevicius, 2015) e da relação ingressos x concluintes (HADDAD ET AL., 2006), mas atualizando essas relações no ano de 2015 para cada graduação. Assim como fizeram os autores, utilizou-se na presente pesquisa o Censo da Educação Superior, mas de 2015, em que foram verificadas as vagas ofertadas para cada graduação e os números de ingressantes no mesmo ano na montagem da relação vagas $\mathrm{x}$ ingressos. E, para a construção da relação ingressos x concluintes, foram considerados, também do Censo da Educação Superior, os números de concluintes em cada graduação em 2015; e, levando em consideração a duração mínima oficial de cada graduação, os números de ingressantes, em 2010, em Medicina; em 2011, em Enfermagem, Fisioterapia, Psicologia, Farmácia, Medicina Veterinária e Odontologia; e, em 2012, nos cursos de Educação Física, Nutrição, Biomedicina, Ciências Biológicas, Fonoaudiologia, Terapia Ocupacional e Serviço Social. Na identificação e no dimensionamento do ensino a distância entre as graduações em todo o período de 1995 a 2015, as variáveis utilizadas foram os cursos, as vagas (nas instituições de ensino públicas e privadas) e os concluintes, através dos dados da modalidade de Ensino a Distância (EAD) de cada ano, no período de 1995 a 2015, dos Censos da Educação Superior do Inep.

\section{Oferta de cursos presenciais: crescimento, privatização e concentração geográfica}

Os dados da tabela 1 evidenciam uma ampliação substancial do total dos cursos das graduações em saúde entre 1995 e 2015, aumentando a sua oferta total de, respectivamente, 1.032 para 5.222, um crescimento de 406,0\%, sendo, até 2004, de 212,3\% (de 1.032 
para 3.223 cursos). Tais números revelam o impacto da política de flexibilização do ensino superior advinda da LDB de 1996 e das políticas públicas de acessibilidade e financiamento para a graduação (PNE, Fies, Prouni), refletindo na expansão da oferta de cursos, tendo em vista que, já em 2011, o total de cursos passou para 4.692 (INEP, 2015B), ou seja, 354,6\% de acréscimo em relação a 1995.

Constatando as políticas de incentivo para o ensino de terceiro grau e a sua expansão, em 1995, para todas as áreas do conhecimento, foram ofertados, no total, 6.252 cursos de graduação, e, em 2015, essa oferta expandiu para 32.028 cursos. A participação das catorze profissões entre a oferta total do ensino superior, em 1995, foi de 1.032 cursos, ou de 16,5\%; e, em 2015, de 5.222 cursos para as catorze formações, representando 16,3\% do total da oferta de cursos de todas as áreas do conhecimento (INEP, 2015B).

Nas graduações em saúde, nota-se (tabela 1) a grande expansão absoluta, entre 1995 e 2015, da oferta de cursos de Biomedicina, de 7 cursos para 285 (3.071,4\% de crescimento e, excepcionalmente, como profissão mais recente, no período de 2000 a 2015); Nutrição, de 42 para 406 cursos (866,7\%); Fisioterapia, de 63 para 560 (788,9\%); Enfermagem, de 108 para 887 (721,3\%); Farmácia, de 59 para 470 (696,6\%); Serviço Social, de 72 para 409 (468,0\%); Medicina Veterinária, de 41 para 221 (439,0\%); Psicologia, de 115 para 560 (387,0\%). E, comparativamente, menores crescimentos em Educação Física, de 140 para 478 cursos (241,4\%); Medicina, de 85 para 257 (202,3\%); Terapia Ocupacional, de 16 para 48 (200,0\%); Odontologia, de 91 para 241 (164,8\%); Fonoaudiologia, de 35 para 79 (125,7\%); e Ciências Biológicas, de 158 para 321 cursos (ou 103,2\% de crescimento).

Essa expansão foi comandada primordialmente pelas instituições privadas de ensino (tabela 1). Se, em 1995, elas participavam com 538 cursos $(52,1 \%)$ do total dos cursos, em 2004, aumentaram para 3.223 (79,0\%), e, em 2015, apresentavam uma oferta de 4.105 cursos $(79,0 \%)$ do total de 5.222 cursos das graduações em saúde no País.

Se Vieira et al. (2006) e Haddad et al. (2006) haviam evidenciado como tendência a privatização do ensino superior em saúde no País no início da década de 2000, em 2015, evidencia-se essa característica como uma realidade incontestável. Assim, pelos dados absolutos de 2015 de cursos públicos e privados da tabela 1, a privatização do total da oferta de cursos foi de $78,6 \%$. Entre as graduações, a privatização dos cursos na Biomedicina foi de 91,0\%; na Fisioterapia, de 88,0\%; em Enfermagem, 82,0\%; Psicologia, 82,0\%; Educação Física, 82,0\%; Serviço Social, 81,7\%; Farmácia, 81,1\%; Nutrição, 81,0\%; Odontologia, 73,4\%; Fonoaudiologia, 69,6\%; Medicina Veterinária, 68,0\%; Ciências Biológicas, 57,0\%; Terapia Ocupacional, 56,0\%; e Medicina, com 55,6\% de cursos privados.

Outra característica que revela o mercado educacional é a iniquidade geográfica da oferta dos cursos de saúde no Brasil. Em 1995 , do total dos cursos, $51,9 \%$ estavam concentrados na região Sudeste; $20,9 \%$ no Sul; $15,6 \%$ no Nordeste; e apenas 7,0\% no CentroOeste e 4,6\% na região Norte (INEP, 2015B). Em 2004, também do total dos cursos, $51,6 \%$ permaneceram concentrados na região Sudeste (São Paulo, com 26,5\%, e Minas Gerais com 13,4\%); $20,7 \%$ no Sul; $15,0 \%$ no Nordeste; $7,4 \%$ no Centro Oeste; e 5,3\% no Norte (INEP, 2015B). Em 2015, houve uma ligeira desconcentração do Sudeste, mas, ainda assim, a região ainda concentrava $45,4 \%$ do total dos cursos (São Paulo, com 23,8\%, e Minas Gerais com $12,3 \%$ do total dos cursos no País), e mais da metade do total dos cursos $(54,6 \%)$ estava distribuída em: $20,3 \%$ no Nordeste; $18,2 \%$ no Sul; $8,8 \%$ no Centro Oeste; e 7,3\% no Norte (INEP, 2015B). 
Tabela 1. Número de cursos das graduações na área da saúde por ano e por instituições de ensino públicas e privadas. Brasil: 1995, 2004, 2015

\begin{tabular}{|c|c|c|c|c|c|c|c|c|c|}
\hline \multirow{3}{*}{ Graduações } & \multicolumn{9}{|c|}{ Cursos } \\
\hline & \multicolumn{3}{|c|}{1995} & \multicolumn{3}{|c|}{2004} & \multicolumn{3}{|c|}{2015} \\
\hline & Público & Privado & Total & Público & Privado & Total & Público & Privado & Total \\
\hline Medicina & 52 & 33 & 85 & 68 & 68 & 136 & 114 & 143 & 257 \\
\hline Enfermagem & 62 & 46 & 108 & 93 & 322 & 415 & 161 & 726 & 887 \\
\hline Odontologia & 46 & 45 & 91 & 54 & 120 & 174 & 64 & 177 & 241 \\
\hline Farmácia & 34 & 25 & 59 & 48 & 189 & 237 & 89 & 381 & 470 \\
\hline Nutrição & 22 & 20 & 42 & 39 & 162 & 201 & 78 & 328 & 406 \\
\hline Ciências Biológicas & 83 & 75 & 158 & 243 & 264 & 507 & 139 & 182 & 321 \\
\hline Medicina Veterinária & 28 & 13 & 41 & 40 & 79 & 119 & 71 & 150 & 221 \\
\hline Fisioterapia & 17 & 46 & 63 & 36 & 303 & 339 & 68 & 492 & 560 \\
\hline Fonoaudiologia & 7 & 28 & 35 & 14 & 85 & 99 & 24 & 55 & 79 \\
\hline Serviço Social & 31 & 41 & 72 & 46 & 116 & 162 & 75 & 334 & 409 \\
\hline Terapia Ocupacional & 5 & 11 & 16 & 9 & 30 & 39 & 21 & 27 & 48 \\
\hline Biomedicina & $2^{\star}$ & $5^{\star}$ & $7^{\star}$ & 7 & 47 & 54 & 26 & 259 & 285 \\
\hline Educação Física & 69 & 71 & 140 & 158 & 311 & 469 & 86 & 392 & 478 \\
\hline Psicologia & 36 & 79 & 115 & 51 & 221 & 272 & 101 & 459 & 560 \\
\hline Total & 494 & 538 & 1.032 & 906 & 2.317 & 3.223 & 1.117 & 4.105 & 5.222 \\
\hline
\end{tabular}

Fonte: Inep. Censo da Educação Superior, 1995, 2000, 2004, 2015. (INEP, 2015b).

${ }^{*}$ Como profissão recente, os dados aparecem no Inep a partir de 2000.

Embora a Constituição Federal, em seu art. 200, tenha estabelecido a ordenação da formação de recursos humanos na área da saúde como atribuição do Sistema Único de Saúde (SUS), percebe-se, diante do intenso crescimento e da privatização dos cursos das catorze graduações, que prevaleceu a lógica de mercado, tornando o setor educacional rentável para as instituições de ensino privadas, o que também espelha a desconexão do setor da educação com o da saúde e com as necessidades sanitárias das populações das regiões menos desenvolvidas e socialmente mais vulneráveis.

Parece, comparativamente, que, além do menor crescimento dos cursos de Medicina e de Odontologia, do alto custo de investimento para implantação e manutenção de cursos e, ainda, da necessidade de corpo docente suficiente e qualificado, houve também o resultado do trabalho da Comissão Interinstitucional de Recursos Humanos (CIRH), a qual assessora o CNS quanto à avaliação de solicitação de criação de novos cursos, limitando a expansão geográfica desnecessária - fato que não ocorreu com a mesma intensidade com a Psicologia, também avaliada pela CIRH.

Nesse processo, há de se considerar as fortes corporações e conselhos da Medicina e da Odontologia, que já se posicionavam de forma opinativa, como previa o Decreto $\mathrm{n}^{\mathrm{o}} 2.306$ (BRASIL, 1997), contra o crescimento de seus cursos e, ao que parece, na lógica de reserva de mercado e de receio quanto à qualidade do ensino, como também foi o caso da resistência corporativa diante da criação do Programa Mais Médicos, em 2013. Entretanto, houve acréscimo de cursos de Medicina em apenas dois anos, ou seja, de 
2013 a 2015, já com a implantação do referido programa, 51 cursos foram criados (20 públicos - sendo 19 federais e 1 estadual - e 31 privados), uma média de 25,5 novos cursos por ano, em contraposição ao crescimento de 70 novos cursos no período de nove anos, de 2004 a 2013, com média de 7,8 novos cursos anuais (INEP, 2015).

Entre as graduações de maior crescimento nos anos de 1995 e 2015 (Biomedicina, Fisioterapia, Enfermagem, Farmácia, Nutrição, Serviço Social, Medicina Veterinária e Psicologia), somente a Enfermagem, através de intensa demanda do seu Conselho Federal (Cofen) - que já opinava desde 2012 sobre abertura de cursos -, da Associação Brasileira de Enfermagem (Aben) e da Federação Nacional de Enfermeiros (FNE), consegue, finalmente, em 2016, a inclusão de avaliação da CIRH nas solicitações de abertura de novos cursos, conforme dispõe o Decreto no 8.754 (BRASIL, 2016).

\section{Oferta de vagas nos cursos presenciais}

O crescimento de vagas corrobora ainda mais o pressuposto de que as políticas públicas para maior acesso ao ensino superior no País expandiram a oferta para a graduação. $\mathrm{O}$ total de vagas para todas as áreas do conhecimento cresceu de 610.355, em 1995, para 3.754.284 vagas, em 2015 (INEP, 2015B). Em todo o período de 1995 a 2015, foram ofertadas 46.777 .136 vagas para a formação superior em todas as áreas do conhecimento, e, entre elas, 7.986.521 vagas (ou 17,1\%) foram abertas para as catorze graduações em saúde (INEP, 2015B).

Dessa forma, no período de 1995 a 2015, foram ofertadas, no total, 1.488.445 vagas para a graduação em Enfermagem; 1.027 .596 para Fisioterapia; 1.011.820 para Psicologia; 857.086 para Educação Física; 653.095 para Farmácia; 540.451 para Nutrição; 504.896 para Ciências Biológicas; 491.961 para Serviço Social, 351.644 para Odontologia; 299.319 para Medicina; 284.592 para Medicina Veterinária;
282.418 para Biomedicina (de 2000 a 2015); 141.813 para Fonoaudiologia; e 51.385 vagas para Terapia Ocupacional (INEP, 2015B).

\section{Concluintes das graduações presenciais em saúde}

Visualizando os dados absolutos da tabela 2, percebe-se que, entre 1995 e 2015 , houve um crescimento total de 52.657 para 179.018 concluintes $(240,0 \%)$ na formação superior dos profissionais de saúde. Prevaleceu a conclusão de cursos através das instituições privadas, com um crescimento de 28.826 para 139.984 concluintes $(386,0 \%)$, conforme a configuração do sistema educacional.

O aumento de concluintes para a Biomedicina foi de 124 para 6.837 entre 2000 (quando aparecem os dados da nova profissão) a 2015 (5.414,0\%); e entre 1995 a 2015 , o número de concluintes para a Nutrição passou de 1.543 para 11.927 (673,0\%); Enfermagem, de 4.733 para 34.640 (632,0\%); Fisioterapia, de 2.422 para 14.505 (499,0\%); Serviço Social, de 2.981 para 12.991 (336,0\%); Medicina Veterinária, de 2.049 para 7.755 (278,4\%); Farmácia, de 3.996 para 14.628 (266,1\%); Terapia Ocupacional, de 246 para 883 (259,0\%); Educação Física, de 5.662 para 14.019 (147,6\%); Psicologia, de 9.799 para 23.285 (138,0\%); Medicina, de 7.194 para 17.042 (137,0\%); Odontologia, de 6.964 para 12.891 (85,1\%); Ciências Biológicas, de 3.566 para 5.808 (63,0\%); e Fonoaudiologia, de 1.378 para 1.807 concluintes $(31,1 \%)$.

À exceção da Terapia Ocupacional, em 2015, a conclusão da formação em saúde foi originária, em sua maioria, das instituições privadas de ensino, de forma coerente com a oferta dos cursos e vagas. Assim, do total absoluto de concluintes de cada formação em 2015 (tabela 2), 6.109 (89,3\%) dos egressos da Biomedicina concluíram sua formação em instituições privadas; 12.595 (87,0\%) dos egressos da Fisioterapia; 29.293 (84,6\%) da Enfermagem; 19.412 (83,4\%) da Psicologia; 
11.632 (83,0\%) da Educação Física; 11.680 (80,0\%) da Farmácia; 9.432 (80,0\%) da Nutrição; 10.204 (78,5\%) do Serviço Social; $9.578(74,3 \%)$ da Odontologia; 4.941 (64,0\%) da Medicina Veterinária; 10.668 (62,6\%) da Medicina; 1.110 (61,4\%) da Fonoaudiologia; 3.060 (52,7\%) das Ciências Biológicas; e a exceção dos 270 concluintes $(30,6 \%)$ da Terapia Ocupacional.

Quanto à distribuição geográfica, em 1995, a região Sudeste concentrou $61,0 \%$ da oferta de concluintes das graduações em saúde (São Paulo, 33,8\%, Rio de Janeiro, 15,8\%, e Minas Gerais, 10,4\%); o Sul formou 17,8\%; o Nordeste, 13,8\%; o Centro-Oeste, $4,9 \%$; e o Norte, $3,4 \%$. Em 2015, a região Sudeste formou 45,2\%\% do total da oferta de concluintes (São Paulo, 24,1\%, Minas Gerais, 10,8\%, e Rio de Janeiro, 8,5\%); o Nordeste, 22,3\%; o Sul, 16,0\%; o Centro Oeste, 9,3\%; e o Norte, $7,2 \%$.

Tabela 2. Número de concluintes de graduações na área da saúde em 1995 e 2015 e número total de concluintes de 1995 a 2015 por instituições públicas e privadas. Brasil: 1995-2015

\begin{tabular}{|c|c|c|c|c|c|c|c|c|c|}
\hline \multirow{3}{*}{ Graduações } & \multicolumn{9}{|c|}{ Concluintes } \\
\hline & \multicolumn{3}{|c|}{1995} & \multicolumn{3}{|c|}{2015} & \multicolumn{3}{|c|}{ 1995-2015 } \\
\hline & Público & Privado & Total & Público & Privado & Total & Público & Privado & Total \\
\hline Medicina & 4.531 & 2.663 & 7.194 & 6.374 & 10.668 & 17.042 & 113.314 & 113.923 & 227.237 \\
\hline Enfermagem & 2.936 & 1.797 & 4.733 & 5.347 & 29.293 & 34.640 & 89.466 & 374.942 & 464.408 \\
\hline Odontologia & 3.064 & 3.900 & 6.964 & 3.313 & 9.578 & 12.891 & 66.266 & 121.485 & 187.751 \\
\hline Farmácia & 2.183 & 1.813 & 3.996 & 2.948 & 11.680 & 14.628 & 61.633 & 156.013 & 217.646 \\
\hline Nutrição & 742 & 801 & 1.543 & 2.495 & 9.432 & 11.927 & 29.766 & 102.191 & 131.957 \\
\hline $\begin{array}{l}\text { Ciências Bioló- } \\
\text { gicas }\end{array}$ & 1.901 & 1.665 & 3.566 & 2.748 & 3.060 & 5.808 & 73.292 & 90.286 & 163.578 \\
\hline $\begin{array}{l}\text { Medicina Vete- } \\
\text { rinária }\end{array}$ & 1.401 & 648 & 2.049 & 2.814 & 4.941 & 7.755 & 43.589 & 53.518 & 97.107 \\
\hline Fisioterapia & 484 & 1.938 & 2.422 & 1.910 & 12.595 & 14.505 & 26.200 & 211.412 & 237.612 \\
\hline Fonoaudiologia & 181 & 1.197 & 1.378 & 697 & 1.110 & 1.807 & 7.678 & 33.657 & 41.335 \\
\hline Serviço Social & 1.272 & 1.709 & 2.981 & 2.787 & 10.204 & 12.991 & 43.130 & 108.985 & 152.115 \\
\hline $\begin{array}{l}\text { Terapia Ocupa- } \\
\text { cional }\end{array}$ & 89 & 157 & 246 & 613 & 270 & 883 & 5.111 & 10.382 & 15.493 \\
\hline Biomedicina & $43^{*}$ & $81^{\star}$ & $124^{\star}$ & 728 & 6.109 & 6.837 & 5.269 & 39.397 & 44.666 \\
\hline Educação Física & 2.612 & 3.050 & 5.662 & 2.387 & 11.632 & 14.019 & 56.518 & 171.576 & 228.094 \\
\hline Psicologia & 2.392 & 7.407 & 9.799 & 3.873 & 19.412 & 23.285 & 61.676 & 255.555 & 317.231 \\
\hline Total & 23.831 & 28.826 & 52.657 & 39.034 & 139.984 & 179.018 & 682.908 & 1.843 .322 & 2.526 .230 \\
\hline
\end{tabular}

Fonte: Inep. Censo da Educação Superior, 1995-2015. (INEP, 2015b).

${ }^{\star}$ Como profissão recente, os dados aparecem no Inep a partir de 2000.

Para melhor constatar a expansão do ensino superior no País, em todo o período de 1995 a 2015, os concluintes em todas as áreas do conhecimento e na modalidade presencial (INEP, 2015B) totalizaram 12.627.671 egressos. Nas catorze profissões de saúde (tabela 2), foram formados, no mesmo período, 2.526.230 profissionais (INEP, 2015B), representando, portanto, $20,0 \%$ do total dos concluintes de todas as áreas do conhecimento.

Entre o total dos concluintes das graduações em saúde (2.526.230), e como 
demonstra a tabela 2, formaram-se, em todo o período, 464.408 enfermeiros (18,4\% do total dos graduados em saúde), 317.231 psicó$\log$ os (12,6\%), 237.612 fisioterapeutas (9,4\%), 228.094 educadores físicos (9,1\%), 227.237 médicos (9,0\%), 217.646 farmacêuticos (8,6\%), 187.751 odontólogos (7,4\%), 163.578 profissionais das ciências biológicas $(6,5 \%)$, 152.115 assistentes sociais (6,0\%), $131.957 \mathrm{nu}-$ tricionistas (5,2\%), 97.107 médicos veterinários ( $3,8 \%), 44.666$ biomédicos (1,8\%), 41.335 fonoaudiólogos (1,6\%) e 15.493 terapeutas ocupacionais $(0,6 \%)$, do total das graduações (INEP, 2015B).

Demonstrando, mais uma vez, a privatização do ensino na saúde (tabela 2), entre o total dos seus concluintes, $73,0 \%$, ou 1.843.322, são oriundos de instituições privadas de ensino. Em cada graduação, as instituições privadas formaram $89,0 \%$ dos fisioterapeutas, $88,2 \%$ dos biomédicos, $81,4 \%$ dos fonoaudiólogos, $80,7 \%$ dos enfermeiros, $80,6 \%$ dos psicólogos, $77,4 \%$ dos nutricionistas, $75,2 \%$ dos educadores físicos, $71,7 \%$ dos farmacêuticos, $71,6 \%$ dos assistentes sociais, $67,0 \%$ dos terapeutas educacionais, $64,7 \%$ dos odontólogos, $55,2 \%$ dos profissionais das ciências biológicas, $55,1 \%$ dos médicos veterinários e 50,1\% dos médicos (INEP, 2015B).

É importante registrar que a ampliação da formação dos profissionais de saúde vem resultando em efeitos positivos na composição da força de trabalho setorial. Segundo os dados da Pesquisa Assistência Médico Sanitária (IBGE, 1992, 2005, 2009, 2014), em 1992, do total dos empregos formais em saúde (1.035.368), excluídos os administrativos, $43,7 \%$ eram ocupados por profissionais de nível superior, aumentando sua participação de 45,4\%, em 2005 (do total de 1.916.642), para 47,8\%, em 2009 (do total de 2.311.026), e para $59,3 \%$, em 2014 (do total de 2.803 .063 empregos). Mas, entre o total dos postos formais de trabalho de nível superior, em 2014 (1.663.335), os médicos ocupavam $58,7 \%$, os enfermeiros, $14,2 \%$, e os odontólogos, $10,4 \%$, sendo todos os $16,7 \%$ restantes dos empregos distribuídos de forma decrescente entre as outras seis profissões: fisioterapeutas, psicólogos, farmacêuticos/bioquímicos, assistentes sociais, nutricionistas e fonoaudiólogos (IBGE, 2014). Evidenciando, portanto, a inexistência da pluralidade e o desequilíbrio das profissões na composição da 'equipe de saúde' no que concerne aos empregos formais do setor.

Tendo em vista o grande crescimento do ensino superior, retratado, principalmente, através do aumento de cursos, das vagas e dos concluintes, pode-se considerar que as políticas de Estado em prol de maior acesso ao ensino universitário resultaram, de fato, na expansão da sua oferta. Necessita-se, entretando, da avaliação dessas políticas com relação aos seus objetivos e resultados, o que não constitui objeto desta análise. O que se destaca é que essa expansão foi alicerçada pelas instituições de ensino privadas, em detrimento das instituições públicas, apesar dos esforços de reestruturação destas últimas, a exemplo do Reuni. E, ainda, que a expansão não deve ser considerada uma sobreoferta de graduações em saúde. No caso dos médicos e dos enfermeiros - respectivamente, entre as menores e as maiores ofertas das graduações -, registrados nos Conselhos até outubro de 2016 (CFM, 2016; COFEN, 2016), quando comparados com a projeção da população brasileira em outubro de 2016, de 206.481.640 habitantes (IBGE, 2016), verifica-se que o Brasil dispõe de apenas 2,1 médicos por 1.000 habitantes e de 2,2 enfermeiros por 1.000 habitantes.

\section{Ociosidade de vagas}

O estudo de Humerez e Jankevicius (2015), que analisou, em 2001 e 2011, e levou em consideração a maior expansão dos cursos e vagas iniciada nos primeiros anos da década de 2000, revelou, através da relação vagas x ingressos, uma elevada ociosidade de vagas, exceto para a Medicina. Esses autores constataram para a formação em Enfermagem uma 
ociosidade de vagas de, respectivamente, em 2001 e em 2011, 3.006 e 54.775 vagas não preenchidas; na Biologia, de 2.796 e 44.033; na Fisioterapia, de 7.500 e 40.239; na Psicologia, de 7.324 e 32.458; na Educação Física, de 4.091 e 29.593; na Farmácia, de 4.120 e 26.623; na Nutrição, de 3.201 e 22.658; no Serviço Social, de 1.562 e 17.437; na Biomedicina, de 319 e 14.403; na Medicina Veterinária, de 1.535 e 6.331; na Fonoaudiologia, de 3.103 e 4.756; na Odontologia, de 2.624 e 4.225; e na Terapia Ocupacional, de 657 e 2.121 vagas não preenchidas em 2001 e 2011.

Atualizando essa mesma relação com os últimos dados disponíveis de vagas e ingressos do Inep, ou seja, de 2015, com exceção da Medicina, persiste a ociosidade das vagas. Assim, em 2015, para a formação em Enfermagem, o não preenchimento foi de 57.123 vagas $(42,5 \%$ do seu total de vagas ofertadas no ano); 35.987 vagas ociosas (42,3\%) na Fisioterapia; 32.659 (52,0\%) na Farmácia; 30.417 (61,5\%) no Serviço Social; 24.572 (37,0\%) na Educação Física; 23.631 (27,2\%) na Psicologia; 19.809 (48,2\%) na Biomedicina; 16.761 (30,0\%) na Nutrição; 13.124 (54,9\%) nas Ciências Biológicas; 6.090 (21,2\%) na Medicina Veterinária; 3.143 (47,4\%) na Fonoaudiologia; 2.130 (7,8\%) na Odontologia; e 1.213 vagas ociosas $(44,3 \%)$ na Terapia Ocupacional (INEP, 2015B).

Por sua vez, a relação ingressos $\mathrm{x}$ concluintes apresenta outra perda significativa, que se soma à perda de vagas proveniente da relação vagas x ingressos. Haddad et al. (2006) constataram através da relação ingressos x concluintes, no período de 1991 a 2004, uma perda média de $50,0 \%$ das vagas para as formações em saúde (exceto para a Medicina), principalmente nas instituições privadas de ensino da região Sudeste, as quais ofertaram mais cursos e vagas. Em 2015 , persistem na relação ingresos x concluintes sinais importantes de perda de vagas, exceto para a Medicina. Entretanto, para a Enfermagem, uma perda de 27.158 vagas (49,4\%); Psicologia, 15.807 (40,4\%);
Fisioterapia, 14.195 (49,4\%); Serviço Social, 12.230 (48,5\%); Nutrição, 11.345 (48,7\%); Farmácia, 10.617 (42,0\%); Biomedicina, 8.844 (56,4\%); Educação Física, 8.057 (31,9\%); Ciências Biológicas, 5.193 (47,2\%); Medicina Veterinária, 4.061 (34,4\%); Odontologia, 3.745 (22,5\%); Fonoaudiologia, 1.289 (41,6\%); e Terapia Ocupacional, perda de 662 vagas $(42,8 \%)$ (INEP, 2015B).

Diferentemente da relação vagas $\mathrm{x}$ ingressos, onde se verifica uma ociosidade de vagas não ocupadas e, assim, de fato, perdidas pela não demanda aos cursos, a relação ingressos $\mathrm{x}$ concluintes, já que considera o período mínimo oficial de cada curso, pode ser superestimada, dado que não leva em conta as repetências dos alunos, prolongando a conclusão do curso. Mas, com taxas elevadas e persistentes desde os anos 1990, como constataram Haddad et al. (2006), revelam, certamente, o abandono de curso.

A evasão no ensino superior que se fez presente nesta análise, também verificada nos estudos citados, parece demonstrar que mesmo os programas, por exemplo, o Prouni e o Plano Nacional de Assistência Estudantil (PNAES) (BRASIL, 2005, 2010), de manutenção de alunos, principalmente os de baixa renda, de cotas raciais e sociais nas graduações, não vêm garantido essa manutenção nem a conclusão dos cursos.

Se, de um lado, o PNE de 2001-2010 previa a oferta de educação superior para pelo ao menos 30,0\% da população de 18 a 24 anos, a conclusão do ensino médio era de 1.771 .420 egressos, em média, ao ano, no período de 2007 a 2010, de acordo com o Censo Escolar da Educação Básica (INEP, 2015A). Ou seja, uma demanda menor do que a oferta de vagas na educação superior, a qual, de acordo com os dados do Censo da Educação Superior, apenas na modalidade presencial, em média, ofertou 2.944.887 vagas ao ano no mesmo período. Se somada a da graduação a distância, a oferta média de vagas cresce para 4.796.485 ao ano, também entre 2007 a 2010 (INEP, 2015B). O PNE de 2014 a 2020 (BRASIL, 2014) 
almeja alcançar 33,0\% da população de 18 a 24 anos inserida na educação superior, mas os egressos do ensino médio ainda não são suficientes, de acordo com os dados disponíveis do Censo Escolar da Educação Básica (INEP, 2015A), ou uma média de 1.851 .970 egressos do ensino médio, entre 2011 e 2012, para uma oferta maior ainda de vagas em todo ensino superior depois do ano de 2010, como, por exemplo, uma oferta total, em 2014 (início do atual PNE), de 6.345.652 vagas, sendo 3.545.294 presenciais e 2.800 .358 vagas de cursos a distância (INEP, 2015B).

Longe de analisar os Planos Nacionais de Educação e o ensino médio - sobretudo por não constituir, também, objeto desta análise -, os dados tanto do Censo da Educação Superior quanto os poucos do Censo da Educação Básica permitem vislumbrar a existência de grandes fragilidades no ensino médio. Como afirma Krawczyk:

A expansão do ensino médio, iniciada nos primeiros anos da década de 1990, não pode ser caracterizada ainda como um processo de universalização nem de democratização, devido às altas porcentagens de jovens que permanecem fora da escola, à tendência ao declínio do número de matrículas desde 2004 e à persistência de altos índices de evasão e reprovação. (KRAWCZYK, 2011, P. 755).

\section{Graduações em saúde a distância: um fato contemporâneo}

Conforme já assinalado, a presença de cursos que oferecem o ensino na modalidade EAD impacta a oferta de vagas no ensino superior. Entre as catorze graduações em saúde, foram identificados nos Censos da Educação Superior de 1995 a 2015, na modalidade EAD, os cursos, as vagas (públicas e privadas) e o número de concluintes entre as graduações em saúde. Dessa forma, esses cursos se fizeram presentes a partir de 2006 para a Fisioterapia e o Serviço Social; desde 2007 para a Enfermagem; desde 2008 para a Educação Física e as Ciências Biológicas (sendo que para esta última formação constam cursos e vagas até 2009); e para a Nutrição a partir de 2014. Desde a criação desses cursos, foram ofertadas, no total, 926.101 vagas, sendo 839.261 para Serviço Social (originárias de 26 cursos, entre eles, 25 privados e 1 público); 75.660 vagas para Enfermagem (de 3 cursos privados); 4.000 para Nutrição (de 1 curso privado); 5.700 para Educação Física (de 1 curso privado); 1.000 para Fisioterapia (de 2 cursos privados); e 480 vagas para Ciências Biológicas (de 8 cursos públicos). No último ano da análise, 2015, constam no respectivo Censo 26 cursos EAD de Serviço Social (excepcionalmente, com 1 curso público), 2 de Enfermagem e 1 curso de formação em Nutrição e em Educação Física, todos ofertados por instituições privadas.

A conclusão de curso na modalidade EAD foi expressiva para o Serviço Social, que, desde 2008, formou 79.280 desses profissionais, representando $46,0 \%$ do total dos concluintes (172.541 de 2008 a 2015, e, entre eles, 93.261 concluintes de cursos presenciais) (INEP, 2015B). Essa performance do EAD de Serviço Social parece refletir a maior facilidade para o ingresso no ensino de terceiro grau, atendendo às expectativas tanto de obtenção de diploma do ensino superior quanto de melhor inserção no mercado de trabalho, ou de crescimento funcional nos empregos. Evidentemente que essa profissão merece análise avaliativa na perspectiva da qualidade do ensino e dos egressos e de suas consequências para o papel desse profissional, principalmente na orientação social junto a indivíduos, grupos e população.

Apesar da expressiva oferta de vagas na modalidade EAD, a partir de 2010, a Educação Física teve 503 concluintes, a Enfermagem 475 e a Fisioterapia 69 (INEP, 
2015B). Independentemente do quantitativo, essas formações exigem uma base teórica sólida e o desenvolvimento de habilidades adquiridas com a prática das técnicas, pontos altamente vulneráveis na formação a distância, tendo em vista a precariedade dos polos. Como constatou Humerez (COFEN, 2016), na formação de enfermeiros, nota-se a existência de polos insuficientes em termos de qualidade para aulas presenciais e práticas do alunado, sem convênios com instituições de saúde para estágios, sem bibliotecas e com larga utilização de professores recém-formados. A Enfermagem, que também possui técnicos de nível médio formados por $\mathrm{EAD}$, através do seu Conselho Federal, vem sendo atuante no sentido de enfrentar a eliminação desse risco com a tramitação de dois projetos de Lei na Câmara dos Deputados: o PL 2.891, de 2015, que modifica a lei do exercício profissional, passando a exigir a formação exclusivamente por meio de cursos presenciais; e o PL 4.930, de 2016, que institui o exame de suficiência para obtenção do registro profissional, como ocorre para os egressos dos cursos de Direito. Primordialmente, essa modalidade de formação na área da saúde representa um risco para a atenção à saúde da população, tendo em vista a complexidade dessas profissões, que têm como seu 'objeto de trabalho' o ser humano, seus corpos e suas mentes.

\section{Conclusões}

A análise da trajetória da formação das catorze profissões de saúde apresenta como característica o persistente crescimento da oferta de cursos, vagas e concluintes de forma mercantilizada e concentrada, ainda, na região Sudeste. Na expansão da oferta de vagas, observa-se uma significativa ociosidade através da relação vagas $\mathrm{x}$ ingressos (com perda, de fato, das vagas) e fortes sinais de ociosidade das vagas na relação ingressos $\mathrm{x}$ concluintes, espelhando esta última, devido à sua persistência, desde os anos de 1990, quanto ao abandono nos cursos de graduação. As duas formas de análise refletem não a sobreoferta de vagas das graduações, mas, sim, problemas, tais como os jovens fora da escola, o declínio de matrículas, a evasão e a reprovação no ensino médio, especialmente ao se considerar, por exemplo, que o País dispunha, em 2016, de apenas 2,1 médicos por 1.000 habitantes e de 2,2 enfermeiros por 1.000 habitantes.

A privatização do ensino superior em saúde se solidificou, mostrando, em prol da acessibilidade e em detrimento das instituições públicas de ensino, a retração do Estado quanto à ordenação da formação de recursos humanos em saúde. Mesmo que por dispositivo constitucional, o setor de saúde público é o responsável por essa ordenação. Essa intensa privatização reduz as chances de acesso à educação superior de jovens de baixa renda e também daqueles provenientes das cotas raciais e sociais, tendo em vista as fragilidades das políticas de acesso, a permanência e a conclusão dos cursos de graduação.

Depara-se, assim, com uma situação de insuficiente comprometimento social com os jovens desde o ensino médio, como, também, com a não ordenação da formação de recursos humanos para o SUS, dada a iniquidade geográfica da oferta das graduações e a presença da educação a distância. Fatores últimos que interferem negativamente no acesso da população (primordialmente, das camadas mais vulneráveis do território nacional) aos profissionais e na qualidade da assistência à saúde.

Hodiernamente, apresentam-se como desafios do Estado, no que tange ao ensino superior em saúde, a reorganização e o ordenamento da oferta de forma articulada entre o setor da educação e o setor da saúde, assentados na responsabilidade pública e na necessidade sanitária da população brasileira e coerentes com os princípios e diretrizes do SUS. 


\section{Referências}

BRASIL. Decreto no 2.306, de 19 de agosto de 1997. Regulamenta para o Sistema Federal de Ensino as disposições contidas no art. 10 da Medida Provisória no 1.477-39, de 8 de agosto de 1997, e nos arts. 16, 19, 20, 45, 46 e \& 1o, 52, parágrafo único, 54 e 58 da Lei no 9.394 , de 20 de dezembro de 1996, e dá outras providências. Diário Oficial [da] União, Poder Executivo, Brasília, DF, 20 de ago. 1997. Seção 1, p. 17991.

Decreto no 3.860, de 9 de julho de 2001a. Dispõe sobre a organização do ensino superior, a avaliação do curso e instituições, e dá outras providências. Diário Oficial [da] União, Poder Executivo, Brasília, DF, 10 de jul. 2001. Seção 1, p. 2.

Decreto no 5.773, de 9 de maio de 2006a. Dispõe sobre o exercício das funções de regulação, supervisão e avaliação de instituições de educação superior e cursos superiores de graduação e sequenciais no sistema federal de ensino. Diário Oficial [da] União, Poder Executivo, Brasília, DF, 10 maio 2006. Seção 1, p. 6.

Decreto no 6.096, de 24 de abril de 2007. Institui o Programa de Apoio a Planos de Reestruturação e Expansão das Universidades Federais (REUNI). Diário Oficial [da] União, Poder Executivo, Brasília, DF, 25 abr. 2007. Seção 1, p. 7.

Decreto no 7.234, de 19 de julho de 2010. Plano Nacional de Assistência Estudantil (PNAES). Dispõe sobre o Plano Nacional de Assistência Estudantil (PNAES). Diário Oficial [da] União, Poder Executivo, Brasília, DF, 20 jul. 2010. Seção 1, p. 5.

Decreto no 8.754, de 10 de maio de 2016. Altera o Decreto no 5.773, de 9 de maio de 2006, que dispõe sobre o exercício das funções de regulação, supervisão e avaliação de instituições de educação superior e cursos superiores de graduação e sequenciais no sistema federal de ensino. Diário Oficial [da] União, Poder Executivo, Brasília, DF, 11 de maio 2016. Seção 1, p. 4.

Lei no 9.394, de 20 de dezembro de 1996. Lei das Diretrizes e Bases da Educação Nacional (LDB). Estabelece as diretrizes e bases da educação nacional.
Diário Oficial [da] União, Poder Executivo, Brasília, DF, 23 dez. 1996. Secão 1, p. 27833.

Lei no 10.172, de 9 de janeiro de 2001b. Plano Nacional de Educação. Aprova o Plano Nacional de Educação para o decênio de 2001 a 2010 e dá outras providências. Diário Oficial [da] União, Poder Executivo, Brasília, DF, 10 jan. 2001. Seção 1, p. 120.

Lei no 10.260, de 12 de julho de 2001c. Dispõe sobre o Fundo de Financiamento ao Estudante do Ensino Superior (FIES) e dá outras providências. Diário Oficial [da] União, Poder Executivo, Brasília, DF, 13 jul. 2001. Seção 1, p. 2.

Lei no 11.096, de 13 de janeiro de 2005. Institui o Programa Universidade para Todos (PROUNI), regulamenta a atuação de entidades beneficentes de assistência social no ensino superior, altera a Lei no 10.891, de 9 de julho de 2004, e dá outras providências. Diário Oficial [da] União, Poder Executivo, Brasília, DF, 14 jan. 2005. Seção 1, p. 13.

Lei no 12.711, de 29 de agosto de 2012. Dispõe sobre o ingresso nas universidades federais e nas instituições federais de ensino técnico de nível médio e dá outras providências. Diário Oficial [da] União, Poder Executivo, Brasília, DF, 30 ago. 2012. Seção 1, p. 1-2.

Lei no 13.005, de 25 de junho de 2014. Aprova o Plano Nacional de Educação (PNE) de 2014 a 2024 e dá outras providências. Diário Oficial [da] União, Poder Executivo, Brasília, DF, 26 jun. 2014. Edição Extra, Seção 1, p. 1-7.

\section{CONSELHO FEDERAL DE ENFERMAGEM}

(COFEN). Ensino a distância de enfermagem preocupa profissionais. Disponível em: <http://cidadedemuriae. com.br/2016/06/23/ensino-distancia-de-enfermagem-preocupa-profissioais/>. Acesso em: 20 jul. 2016.

Enfermagem em Números. Disponível em:

$<$ http://www.cofen.gov.br/enfermagem-em-numeros $>$. Acesso em: 27 out. 2016. 
CONSELHO FEDERAL DE MEDICINA (CFM).

Estatística. Disponível em: <portal.cfm.org.br/>. Acesso em: 27 out. 2016.

HADDAD, A. E. et al. A Trajetória dos Cursos de Graduação em Saúde 1991-2004. Brasília, DF: INEP, 2006. (v. 15).

HUMEREZ, D. C.; JANKEVICIUS, J. V. Reflexão sobre a formação das categorias profissionais de saúde de nível superior pós diretrizes curriculares. Brasília, DF: Cofen, 2015. Disponível em: <http://www.cofen.gov.br/reflexão-sobre-a-formação-das-categorias-profissionais-de-saúde-de-nível-superior-pós-diretrizes-curriculares_-35183.html>. Acesso em: 4 ago. 2016.

\section{INSTITUTO BRASILEIRO DE GEOGRAFIA E} ESTATÍSITICA (IBGE). Pesquisa Assistência Médico Sanitária. Rio de Janeiro: IBGE, 1992.

Pesquisa Assistência Médico Sanitária. Rio de Janeiro: IBGE, 2005.

Pesquisa Assistência Médico Sanitária. Rio de Janeiro: IBGE, 2009.

Pesquisa Assistência Médico Sanitária. Rio de Janeiro: IBGE, 2014

Projeção da população do Brasil e das Unidades da Federação. 2016. Disponível em: <www.ibge.gov.br/ apps/população/projeção/>. Acesso em: 27 out. 2016.

INSTITUTO NACIONAL DE ESTUDOS E PESQUISAS EDUCACIONAIS ANÍSIO TEIXEIRA

(INEP). Educação Básica: Censo Escolar: resumos técnicos. Brasília, DF: INEP, 2015a. Disponível em: <http://inep.gov.br/web/guest/resumos-tecnicos1>. Acesso em: 27 jun. 2017.

Censo da Educação Superior: resumos técnicos. Brasília, DF: INEP, 2015b. Disponível em: <http://inep. gov.br/web/guest/resumos-tecnicos1>. Acesso em: 27 jun. 2017.

KRAWCZYK, N. Reflexões sobre alguns desafios do ensino médio no Brasil hoje. Cadernos de Pesquisa, São Paulo, v. 41, n. 144, p. 752-769, set./dez. 2011.

PIERANTONI, C. R. et al. Graduações em Saúde no Brasil: 2000-2010. Rio de Janeiro: IMS/UERJ, 2012.

VIEIRA, A. L. S. et al. Panorama das Graduações em Saúde no Brasil-2003. In: BRASIL. Ministério da saúde. Secretaria de gestão do trabalho e da educação na saúde. (Org.). Dinâmica das Graduações em Saúde no Brasil: subsídios para uma política de recursos humanos. Brasília, DF: Ministério da Saúde, 2006. p. 25-38.

VIEIRA, A. L. S.; AMÂNCIO-FILHO, A. Perspectivas de Mudanças no Sistema de Ensino. In: BRASIL. Ministério da saúde. Secretaria de gestão do trabalho e da educação na saúde. (Org.). Dinâmica das Graduações em Saúde no Brasil: subsídios para uma política de recursos humanos. Brasília, DF: Ministério da Saúde, 2006. p. 263-270.

Recebido para publicação em outubro de 2016

Versão final em maio de 2017

Conflito de interesses: inexistente

Suporte financeiro: não houve 